niecki salientaram, explìcitamente, que o conhecimento de senso comum é insuficiente para orientar a intervenção deliberada do homem no contrôle dos problemas sociais e lançaram as bases das teorias modernas da desorganização da personalidade, da desorganização social e da diferenciação sociopática do comportamento humano ou do funcionamento das instituições sociais. Mau grado a feição antiquada da apresentação dos materiais, a excessiva cópia de dados empíricos inexplorados teòricamente e o envelhecimento inevitável de muitas análises consistentes e significativas na ocasião, esta obra ainda constitui uma leitura fundamental para quem pretenda devotar-se à carreira científica na sociologia. Ela se recomenda tanto aos que se iniciam nos seoredos da pesarisa sociológica, quanto aos que procuram inspirações mais vastas para o labor científico original em nosso campo.

\title{
Florestan Fernandes
}

MICHEL LEIRIS: La possession et ses aspects théâtraux chez 'es éthiopions de Gondar. 103 págs. L'Homme, Cahiers d'Ethnologie, de Géographie et de Linguistique. Plon, Paris, 1958.

Pequena publicacão dividida em cinco capítulos e dedicada ao ectudo da possessão com a finalidade principal de verificar o que nela pode haver de convencional, de mera representacão ou paródia. num grupo sónioculturalmente delimitado, a saber, no grupo etíope de Gondar, Abissínia.

Os cinco capítulos, precedidos de uma introducão, tratam. sucessivamente, do culto dos Zar e do xamanismo; da possessão como divertimento f: expressão estética; dos Zar como símbolo de um modo de ser e como promotores de uma acão: da consciência e inconsciência entre os protagonistas das renas de possessão; do teatro representado e teatro vivido no culto dos 7 ar.

$\mathrm{Na}$ intrnducão. o autor. citando Marcel Griaule, (Le livre de recettes d'un dabtar ahvcsin: (...) "très solvent les malades (du Zar) sont des maniaques plus au moins sincères. dont les bouffonneries et les chants étonnent les gens". (...) "Beanconp de ces prétendus 'Zar sont des simulateurs on quête d'amus^ment ou de honne chère". ). encontra uma sugestão de trabalho e. dentro dessa perspectiva, propñe-se verificar o aspectn teatral da possessão, isto é, as práticas cujo fim essencial parece o de divertir uma assistência (págs. 9-10).

Dá comêço ao primeiro capítulo com mais uma citacão (Jean Filliozoat, Magie et médecine). Hesta vez sôbre o xamanismo siberiano, correlacionando-o com a instituição dos Zar (pág. 13). Em seguida, o autor, com elegância e clareza (traços êsses que sem dúvida pôde cultivar nas suas anteriores publicações de estética e de poesia), conta-nos como se dá a possessão pelos Zar, as suas diferentes rategorias, o culto que se lhes dedida, as iniciações que dêle decorrem, enfim, estas coisas:

Quando um Zar tem preferência por uma pessoa, passa a dar-lhe tôdas as características de um doente; assediando-a, buscando transformá-la num instrumento seu de comunicação, não lhe dá tréguas. Mas o que são os Zar? (O autor, talvez em vista das informações já publicadas, não cuida dĉsse pormenor). São espíritos e grupos de espíritos que de um modo ou $d_{t}$ outro se interessam por tôdas as atividades humanas. Alguns dêles, na Etiópia, são considerados como os espíritos de antigos magos ou, pelo menos, como tendo uma linhagem humana històricamente definida (pág. 14) . Em tôrno dos Zar desenvolve-se um culto e êste dá lugar às iniciações (pág. 
15), mas isso não implica na impossibilidade de serem os Zar transmitidos por herança no seio de uma mesma família ou de feticeiro para algum discípulo predileto (págs. 14 e 15). Logo de início, o paciente tomado pelo Zar, manifesta durante o transe tudo quanto possa caracterizar e identificar êsse Zar e, a partir dessas referências, o especialista (feiticeiro) passa a educar - "cavalo". Há tomadas mais ou menos permanentes que se efetuam, às vêzes, em lugares públicos, mas o culto do Zar envolve cerimônias especiais para a sua invocação. O neófito é coagido a aceitar a possessão, e' a tomada perfeita, de modo geral, só se verifica depois de diversas reuniões. Em seguida finalmente, o iniciado aprende o gurri (serviço) devido a seu Zar e ¿e inteira das hierarquias dos Zar, que há Zar para cada tipo de neófito e para cada grupo de tipos de neófitos, que há Zar de sexo masculino, como de sexo feminino, etc. O iniciado tem pela frente uma longa carreira. Conquista a posição de curador (curandeiro). Organiza uma confraria e pode investir novos curadores. No interior de cada confraria, estabelece-se uma hierarquia de funções e de autorialade conforme a maior ou menor importância do Zar de cada um dos seus membros, e essa importância depende lo sacrifício propiciatório que cada um pode fazer. Segundo a sua qualidade, valor ou raridade, manifesta-se um Zar mais ou menos importante. Um sacrifício menor, o da galinha, por exemplo, atrairá apenas um wereza, espírito menor e auxiliar. Considera-se iniciado aquêle que conhece os sinais e o nome do seu Zar e sabe como tratá-lo e invocá-lo, e tais conhecimentos lhe valem como salvo-conduto quando fora do grupo ou de sua confraria. Deve haver rivalidades entre os iniciados. "D'une manière générale, on constate qu'entre adeptes l'accusation d'imposture est parfois ouvertement portée" (pág. 21). E pode também acontecer que entre os neófitos encontrem os Zar de categoria inferior campo aberto para as suas mentiras e imposturas (ibidem), apresentando-se como Zar de alta categoria.

A possessão caracteriza o paciente como enfêrmo nervoso benigno, diz Leiris, citando mais uma vez Griaule (le livre de recettes d'un dabtara...) e provoca neles uma espécie de “...maladie (...) qui consiste (..) en un développement exagéré des sentiments chevaleresques dont s'honore tout Abyssin. L'individu atteint, (...) chante constament des thèmes de guerre et raconte ses merveilleuses aventures de chasse" (págs. 23-24). Têm, pois, os indivíduos com a instituição dos Zar excelente oportunidade para dar expansão às suas vaidades.

No segundo capítulo o autor observa que as manifestações exteriores do Zar obedecem a uma periodicidade regulada pelo calendário e pelas estações do ano. Incrementam-se por ocasião das festas religiosas e nas épocás de fartura, escasseiam e desaparecem quando as condições climatéricas e econômicas são desfavoráveis. Nas épocas propícias, os possuídos apresentam-se em grande número nos lugares públicos ou onde haja aglomeração popular. São imediatamente reconhecíveis e identificados como criaturas de eleição dos Zar pela sua capacidade de falar brilhantemente, recitar, cantar, dançar, manejar armas de guerra, etc. As cantigas e o terçar simulado de armas bélicas valem por um prelúdio para a possessão e parecem obedecer às linhas de um rito propiciatório à tomada. Ora, isso tudo parece exigir do possuído certa capacidade de representação. Há casos em que se percebe ser a tomada simples representação ou divertimento e, então, a paródia visa as instituições jurídicas e religiosas ou é uma comédia improvisada sôbre os costumes. Mas, mesmo simulada, a possessão é aprovada pelo público.

O autor inicia o 3.0 capítulo com duas perguntas: "Des faits qui viennent d'être rapportés, il ressort que le théâtre en tant que tel a sa place 
dans certaines des cérémonies auxquelles donne lieu le culte des zâr. Faut-il voir là quelque chose de plus ou moins fortuit? Ou le zâr serait-il, dans son essence même, un personnage typique dont la manière d'être se projete dans une action mimée et parlée, soit, en quelque sorte, un "caractère" de théâtre?" (pág. 59). Em seguida, observa que no trato diário no interior das confrarias, certos Zar se manifestam como destinados a funções bem definidas, tomando o aspecto de verdadeiras dramatis personae. O possuído representa sempre o espírito que nele se incorpora. Essas dramatis personae encarregam-se dos mais variados misteres da vida quotidiana e 'passam a formar uma verdadeira galeria de personagens característicos ligados a uma ação, como se não tivessem outra razão de ser senão determinar e significar essa ação e, nesse ponto, conforme o autor, assemelham-se aos personagens de teatro, pois que êstes não existem a não ser em função de acontecimentos cênicos que condicionam e nos quais seu caráter encontra uma ilustração. De tal maneira os Zar ponteiam as atitudes e os valores socialmente consagrados que podem simbolizar um modo de ser nacional e apresentar-se, na terapêtica, ccmo crpaciclictis de trabalhos bem definidos.

Da consciência e da inconsciência da possessão, êsse o problema que o Autor procura enfrentar no $4 .^{\circ}$ capítulo. Parece-lhe difícil o contrôle da situação, visto que é regra comum demonstrar o possuído, após o transe, absoluta ignorância do que aconteceu. Em alguns casos, tem-se a impressão de que há perfeita inconsciência; em outros, simples justaposição de entidade que se manifesta e "cavalo" que lhe concede campo de ação, sem nela intervir voluntàriamente. Nos primeiros, a integração é completa; nos segundos, dá-se apenas a execução de um ritual decorrente das experiências vividas em relação ao processo da tomada.

No último capítulo, Leiris continua a insistir sôbre a distinção entre possessão autêntica e possessão convencional. Considera as atitudes populares perante a tomada simulada: são de tolerância e acatamento, devido, talvez, a um generalizado espírito de piedade e fé. No entanto, há, também, entre êsses dois tipos extremos de possessão, uma longa série de formas intermediárias, em que os pacientes, aproveitando-se da tomada (resguardados pela "tomada"), praticam atos que em circunstâncias normais não teriam coragem de fazer; criticam situações e acontecimentos; na expectativa de uma cura, executam mecânicamente as coisas preceituadas pelo ritual, pouco se interessando com a impressão que possam causar nos espectadores, enfim, buscando "màgicamente" a satisfação de uma necessidade sua. E acontece que êsses casos são tão numerosos e freqüentes que já se não pode tomá-los como simples representação ou divertimento, mas sim como expressão de crenças generalizadas.

O livro, apesar de interessante, apresenta falhas mais ou menos graves.

Em primeiro lugar, entre falhas menores e toleráveis, falta-lhe uma linha clara no sentido de coerência e continuidade no tratamento dos assuntos. Nem bem apresentados, são deixados de lado para retomadas posteriores, e isso obriga o leitor ao trabalho de reconstituí-los, colhendo aqui e acolá os seus fragmentos. Atabalhoadamente é que se vai sabendo que os Zar têm sexo, formam hierarquias, etc.

Em seguida, ainda falha menor, a figura central do culto que pretendeu estudar, os Zar, não mereceu sequer uma nota explicativa em rodapé. Ora, queremos crer que, mesmo nas obras altamente especializadas, certos conceitos básicos, embora transformados em lugares-comuns para os especialistas, nunca dispensam uma apresentação que venha conectar a contribuição nova ao corpo já assentado de conhecimentos. 
E não há nenhuma nota consistente e substancial a respeito da iniciação ao culto dos Zar. Nenhuma informação sôbre as atividades mágico-religiosas dos possuídos pelos Zar nos períodos não propícios às grandes concentrações populares.

Há, ademais, falhas capitais.

Do ponto de vista metodológico, não teria sido mais razoável, mais certo e mais prudente ter o Autor procurado verificar nos grupos sócioculturais vizinhos e, em seguida, nos grupos africanos mais afastados (Eritréia e Sudão), as instituições congêneres à dos Zar para fins de filiação e comparação? Não resta dúvida que o xamanismo pode ser empregado como um conceito classificatório, para abordagem de assunto que nêle se enquadre; mas, para sempre, não. Porventura, o estudioso não viria a correr o perigo de reduzir a uma fórmula consagrada tôda uma série nova de situações que sob certos aspectos nada têm a ver com ela?

$\mathrm{E}$, finalmente, há a falha que, para nós, faz dêste livro um lamentável equívoco.

A indagação, que se estende como têma único pelos cinco capítulos, possessão autêntica ou possessão simulada, nunca teria sido feita por um antropólogo. Poder-se-ia tomar em dois sentidos o que o Autor 'chama de possessão autêntica: um psicológico e outro antropológico. Do ponto de vista psicológico, a questão se resumiria na verificação do grau de inconsciência do indivíduo durante a tomada ou transe, e possessão autêntica seria o estado em que o indivíduo, tendo recorrido a meios mecânicos, medicinais ou seja lá o que fôr, tem sua consciência obnubilada e passa a agir ao impulso de outros elementos da vida psíquica, ou, pedindo vênia aos psicólogos, da vida sócio-cultural profundamente calcados na esfera do inconsciente. Nesse sentido sim é que se justificaria a preocupação do Autor, caso o seu trabalho não fôsse de etnologia. Do ponto de vista antropológico, a coisa é considerada diferentemente. Seria fora de propósito estar a repetir aqui tudo o que já se propôs a respeito de cultura e vida social, mas, para nós, possessão autêntica é isto: um estado especial de comportamento em que o indivíduo, consciente ou inconscientemente, emocionalmente dominado por uma crença ou apenas executando um ato de acôrdo com rituais pré-estabelecidos, funciona como meio veiculador de elementos mágicos e religiosos de uma cultura que, por sua vez, ainda esteja a corresponder às necessidades, solicitações e experiências de uma dada sociedade. Dessa maneira a possessão é sempre autêntica, e mesmo perante os casos em que há charlatanismo, impostura ou paródia, ela ainda é autêntica, porque pode estar a pontear os processos de mudança social, de secularização. Enfim, desde que a possessão corresponda às solicitações da vida sócio-cultural, ela é sempre autêntica ou verdadeira.

Tivesse o Autor elaborado um livro com menos veleidades, teríamos ganho mais uma monografia muito interessante sôbre crenças e práticas mágico-religiosas.

\section{O. E. Xidieh}

HANS HIMMELHEBER: Der gute Ton bei den Negern. 104 págs. Verlag Richters \& Co., Heidelberg, 1957. (Preço: DM 6,80).

Hans Himmelheber empreendeu ao todo seis expedições etnológicas à África Negra. Trabalhou na Libéria, na Costa do Marfim, no Sudão Francês, no Camerum, no Gabon e no Congo Belga. São, assim, bastante ex- 